\title{
044 \\ In vitro multiplication of Wthnia somnifera auxiliary buds for mass propagation
}

\author{
P S Warakagoda, D L C Kumari and S Subasinghe \\ Department of Crop Science, Faculty of Agriculture, University of Ruhuna, Sri Lanka
}

\begin{abstract}
Wthnia somnifera of family Solanaceae commonly known as Amukkara or Ashwaganda is an important medicinal perennial herb with long tapering roots. The roots are widely used in ayurvedic inedicine and prescribed for hiccup, female disorders. cough and rheumatism. Wild and cultivated forms are available and cultivated plants differ in morphological and therapeutical action from wild ones. The annual requirement of $42347 \mathrm{~kg}$ is imported from India spending Rs. 2, 840, 449 (IUCN , 2005). Development of a method for in vitro mass production of this valuable species would substantially reduce the import cost and generate employment opportunities. This study was conducted to develop an in vitro protocol for mass production of $W$. somnifera.
\end{abstract}

In vitro grown seedlings of $\mathrm{W}$. somnifera were used to excise single nodal cuttings and cultured on MS (Murashige \& Skoog. 1962) medium. The effect of NAA $(0.0 .1,0.2 \mathrm{mg} / \mathrm{l})$ in combination with $\operatorname{BAP}(0.5,1.0,1.5 \mathrm{mg} / \mathrm{l})$ on shoot proliferation was tested in solid and liquid MS media containing two levels of sucrose ( $3 \%$ and $4 \%$ ). Proliferation (number of plantlets produced) was observed at weekly intervals.

Highest shoot proliferation rate ( $1: 20)$ was observed in solid MS medium containing $3 \%$ sucrose and $1.5 \mathrm{mg} / \mathrm{l} \mathrm{BAP}$ after two months. In solid MS medium with $4 \%$ sucrose and $1.0 \mathrm{mg} / \mathrm{l} \mathrm{BAP} 1: 10$ shoot proliferation rate was observed after two months. During the same time period 1:15 shoot proliferation rate was observed in solid MS medium with $3 \%$ sucrose, $0.5 \mathrm{mg} / \mathrm{l} \mathrm{BAP}$ and $0.2 \mathrm{mg} / \mathrm{l} \mathrm{NAA}$. where 1 : 12 proliferation rate was observed when BAP concentration increased up to $1.0 \mathrm{mg} / \mathrm{l}$. Solid MS media both with $3 \%$ and $4 \%$ sucrose levels and $0.5 \mathrm{mg} / \mathrm{l} \mathrm{BAP}$ showed some proliferated shoots while other solid cultures were not proliferated. However cultures containing NAA in addition to BAP enhance rooting of proliferated shoots before transferring the separated shoots to rooting media. The explants in liquid MS medium with $4 \%$ sucrose and $1.0 \mathrm{mg} / \mathrm{BAP}$, proliferation initiated in one week and gave 1:40 shoot multiplication rate after two months. Rest of the liquid cultures with different BAP and NAA combinations were not proliferated within the same time duration.

Finally it can be concluded that highest shoot proliferation of $W$. somnifera through single nodal cuttings can be obtained on liquid MS medium with $4 \%$ sucrose and $1.0 \mathrm{mg} / \mathrm{l} \mathrm{BAP}$.

\section{5}

\section{Development of new cultivation technology for straw mushroom (Volvariella volvacea) using locally available raw materials}

\author{
A S Nissanka', P Rajapakshe ${ }^{2}$ and R H M K Ratnayake ${ }^{1}$ \\ 'Department of Horticulture and Landscape Gardening, Wayamba University of Sri Lanka, Sri Lanka \\ 2Regional Agricultural Research and Development Centre, Gonawila, Sri Lanka
}

Paddy straw mushroom (Volvariella volvacea) is an edible mushroom variety which can be cultivated under tropical and sub tropical conditions. In Sri Lanka, though the majority of farmers grow oyster mushroom they are willing to undertake other mushroom types, including straw mushroom and milky mushroom. Straw mushroom cultivation is highly rewarding because of the favourable climatic conditions in Sri Lanka and the abundant availability of raw materials. The existing outdoor method for straiv mushroom cultivation introduced by the Department of Agriculture (DOA) gives low or/and irregular yield. As the optimum environmental conditions are crucial in straw mushroom production, an indoor cultivation method using a polythene house was tested with the existing outdoor method. Cotton waste and paddy straw were used as the growing media in both outdoor and indoor conditions under four treatments viz, paddy straw compost in polythene house (T1), cotton waste compost in polythene house (T2), paddy straw in outdoor environment (T3) and cotton waste in outdoor environment (T4), arranged in a Completely Randomized Design with three replicates. The results revealed that,

Proceedings of the International Forestry and Environment Sympositum 2006 of the 